\title{
Digital Health Interventions in Prevention, Relapse, and Therapy of Mild and Moderate Depression: Scoping Review
}

Pinar Tokgöz ${ }^{1^{*}}$, MPH; Robert Hrynyschyn ${ }^{2 *}$, MPH; Jessica Hafner ${ }^{1^{*}}$, MPH; Simone Schönfeld ${ }^{1,3,4}$, MPH; Christoph Dockweiler $^{1 *}$, Prof Dr

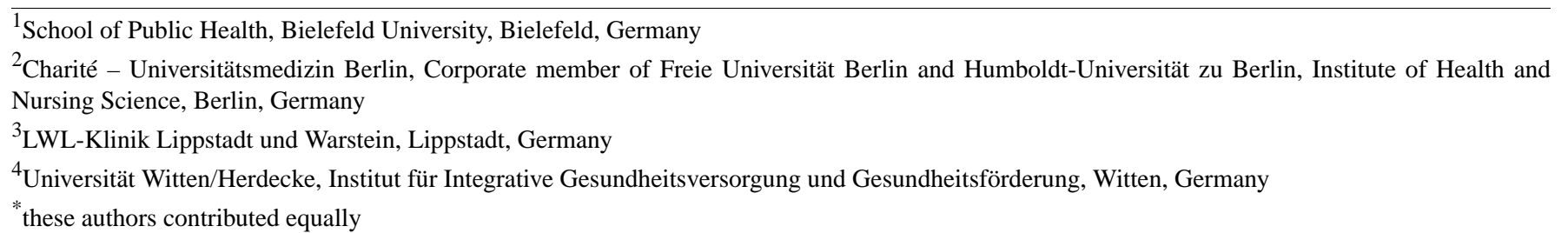

Corresponding Author:

Pinar Tokgöz, MPH

School of Public Health

Bielefeld University

Universitätsstraße 25

Bielefeld, 33615

Germany

Phone: 4952110667136

Email: pinar.tokgoez@uni-bielefeld.de

\begin{abstract}
Background: Depression is a major cause for disability worldwide, and digital health interventions are expected to be an augmentative and effective treatment. According to the fast-growing field of information and communication technologies and its dissemination, there is a need for mapping the technological landscape and its benefits for users.

Objective: The purpose of this scoping review was to give an overview of the digital health interventions used for depression. The main goal of this review was to provide a comprehensive review of the system landscape and its technological state and functions, as well as its evidence and benefits for users.

Methods: A scoping review was conducted to provide a comprehensive overview of the field of digital health interventions for the treatment of depression. PubMed, PSYNDEX, and the Cochrane Library were searched by two independent researchers in October 2020 to identify relevant publications of the last 10 years, which were examined using the inclusion and exclusion criteria. To conduct the review, we used Rayyan, a freely available web tool.

Results: In total, 65 studies were included in the qualitative synthesis. After categorizing the studies into the areas of prevention, early detection, therapy, and relapse prevention, we found dominant numbers of studies in the area of therapy ( $\mathrm{n}=52$ ). There was only one study for prevention, 5 studies for early detection, and 7 studies for relapse prevention. The most dominant therapy approaches were cognitive behavioral therapy, acceptance and commitment therapy, and problem-solving therapy. Most of the studies revealed significant effects of digital health interventions when cognitive behavioral therapy was applied. Cognitive behavioral therapy as the most dominant form was often provided through web-based systems. Combined interventions consisting of web-based and smartphone-based approaches are increasingly found.

Conclusions: Digital health interventions for treating depression are quite comprehensive. There are different interventions focusing on different fields of care. While most interventions can be beneficial to achieve a better depression treatment, it can be difficult to determine which approaches are suitable. Cognitive behavioral therapy through digital health interventions has shown good effects in the treatment of depression, but treatment for depression still stays very individualistic.
\end{abstract}

(JMIR Ment Health 2021;8(4):e26268) doi: $\underline{10.2196 / 26268}$

\section{KEYWORDS}

digital health; depression; scoping review; health care 


\section{Introduction}

Depressive disorders are among the most significant and widespread diseases, and their relevance will continue to increase in the coming years. Nearly 300 million people are affected worldwide [1]. Depressive disorders have a high risk of chronicity and are associated with a substantially increased probability of developing further comorbidities with corresponding effects on the quality of life of those affected. Psychiatric care is facing different structural problems of care, with underuse and misuse of care that is evident in practice [1]. Barriers to access to psychiatric specialists or psychotherapeutic care, lack of cross-sectoral and interdisciplinary care, and long waiting lists are also challenging. It is estimated that less than $50 \%$ of those currently affected receive therapy that is appropriate to their needs and requirements according to current scientific criteria. Although there is an increasing awareness of mental health issues, accessibility to health care has been a key problem [2].

Against this background, psychological, psychotherapeutic, and psychiatric care are experiencing remarkable developments in technology-supported care concepts. A broad spectrum of digital health interventions (DHIs) in psychiatric care already exist today [3]. DHIs enable new forms of interaction and knowledge-based reproduction in the field of health. The constantly growing number of interventions extends from outpatient digital health care programs to telephone, video, or text-based interactions with the therapist and complex online-based intervention programs. Unlike face-to-face treatment, such support systems are easily accessible and standardized, and they can reduce the fear of stigmatization, as they can be used in private and at the convenience of the patient [3].

A steadily increasing amount of empirical data show first indications of patient-related benefits of DHIs, especially the reduction of depressive symptoms; improvement in quality of life; and reduction of direct, indirect, and intangible costs [3]. These potential benefits could be effective for patients and the health system if successful acceptance of DHIs is achieved [4].

This scoping review is part of a research project that examines the multiperspective and participatory development of technology-supported care for people with depressive disorders. The purpose of this scoping review was to give an overview of DHIs used in different fields of depression care. The main goal was to provide a comprehensive review of the system landscape and its technological state and functions, as well as the evidence and benefits for users.

To this end, the following research questions have been addressed:

- What types of DHIs for the treatment of mild and moderate depression have been developed, and how can the functions be described?

- How can the benefits of DHIs in the care of mild and moderate depression be described?

\section{Methods}

\section{Overview}

A scoping review has been conducted to identify knowledge gaps, set research agendas, and identify implications for intervention development. Although scoping reviews are related to systematic reviews, they differ in numerous ways. Scoping reviews present a broader overview of evidence pertaining to a specific topic, irrespective of study quality [5], useful when emerging topics are discussed to clarify key concepts and research gaps. Systematic reviews focus more on specific research questions with a priori defined criteria. Therefore, scoping reviews generate hypotheses, while systematic reviews focus more on testing hypotheses [6]. Results were reported according to the Preferred Reporting Items for Systematic Reviews and Meta-analyses (PRISMA) guidelines of systematic reviews because there are no reporting guidelines for scoping reviews. Research questions and inclusion criteria were adapted from Arksey and O'Malley [5].

\section{Inclusion and Exclusion Criteria}

The following criteria have been developed in coordination with the partners of the research project. The inclusion criteria comprised (1) all DHIs for the treatment of depression, (2) quantitative study design, (3) language: English or German, and (4) published between 2010 and 2020 since the technological development of DHI is dynamic. Exclusion criteria were (1) study participants aged younger than 18 years, (2) no diagnosis of depression, (3) severe course of illness, (4) psychotic symptoms, (5) concurrent medication therapy, or (6) DHIs with no clear relation to depression treatment.

\section{Literature Search}

The search was conducted in October 2020 in the databases PubMed, PSYNDEX, and the Cochrane Library. The following search strategy was used: (depression OR depressive disorder OR depressive episode) AND (online based* OR mobile* OR ehealth* OR "electronic mental health" OR "e-mental health" OR online-based* OR internet-based* OR web-based* OR computer-based).

\section{Data Extraction}

The articles were extracted using standardized table formats. To provide an overview of the aspects of DHIs for depression considered here, the following taxonomy is presented in the tables:

- Authors, year, country, and funding of the study

- Study design

- Study period

- Sample size information

- Technology description and functions

- Relevant outcomes and effects

Moreover, the results were analyzed regarding the effects of the reduction of depressive symptoms and specific characteristics of the DHI. For this purpose, contingency tables were used to show frequency distributions between the benefit and the technology used and the benefit and the therapy form 
used. Furthermore, graphs were built to show which functions have been used by the different therapy forms.

\section{Results}

\section{Study Selection}

In total, 3040 publications were identified. These publications were transmitted to Rayyan, which is a free web tool designed to help researchers conducting systematic reviews. Using this program, the 2 independent researchers (PT and RH) screened the articles according to inclusion and exclusion criteria. In case of disagreement, consensus has been made by the opinion of a third researcher $(\mathrm{JH})$. A total of 65 studies were included in the qualitative synthesis (Figure 1).

In a first step, the field of depression care was categorized in 4 application areas: prevention (1 study identified), early detection (5 studies), therapy (52 studies), and relapse prevention (7 studies; Figure 2). In a further step, this standardization enabled technology mapping and a detailed description of the technologies and their benefits.

Figure 1. PRISMA flow diagram of literature search and selection process [7].
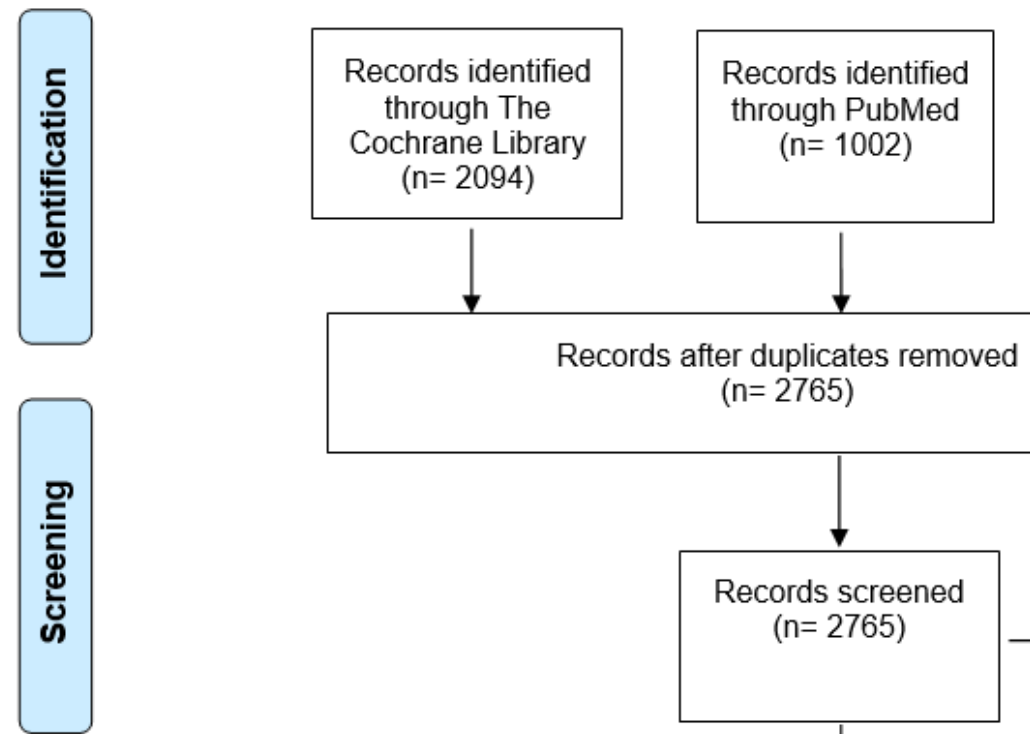

Records identified through PubMed $(n=1002)$

$(n=2765)$

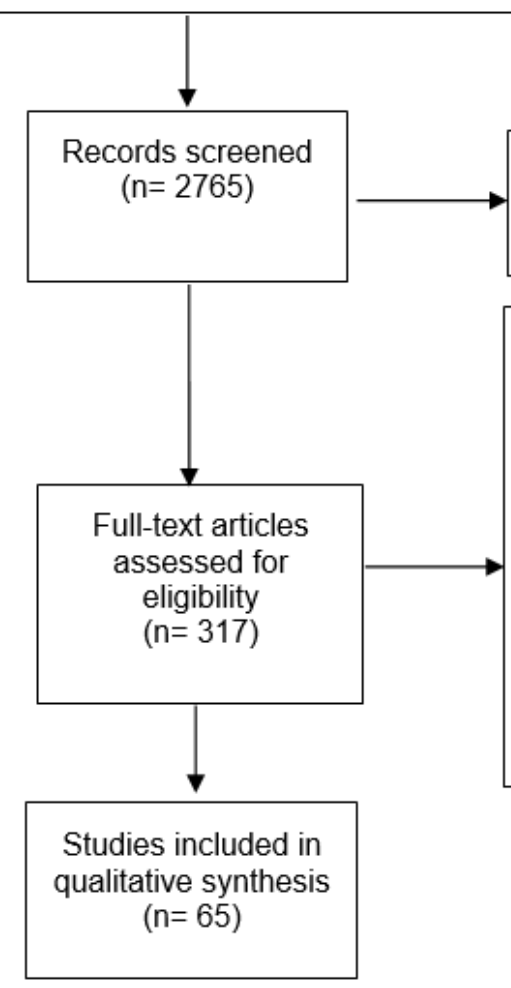

Records identified through Psyndex $(n=144)$

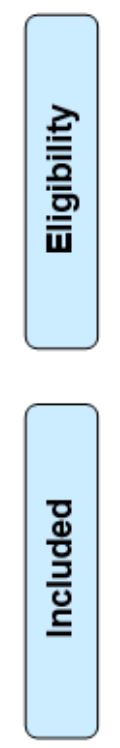
Records excluded
$(\mathrm{n}=2448)$

Full-text articles excluded with reason $(n=252)$

Wrong study design $(n=72)$ Wrong population $(n=58)$

Unfinished study $(n=48)$ Wrong intervention $(n=36)$ Wrong outcome $(n=27)$

Wrong publication type $(n=8)$ Foreign language $(n=2)$ No full-text $(n=1)$ 
Figure 2. Classification of digital health intervention application areas.

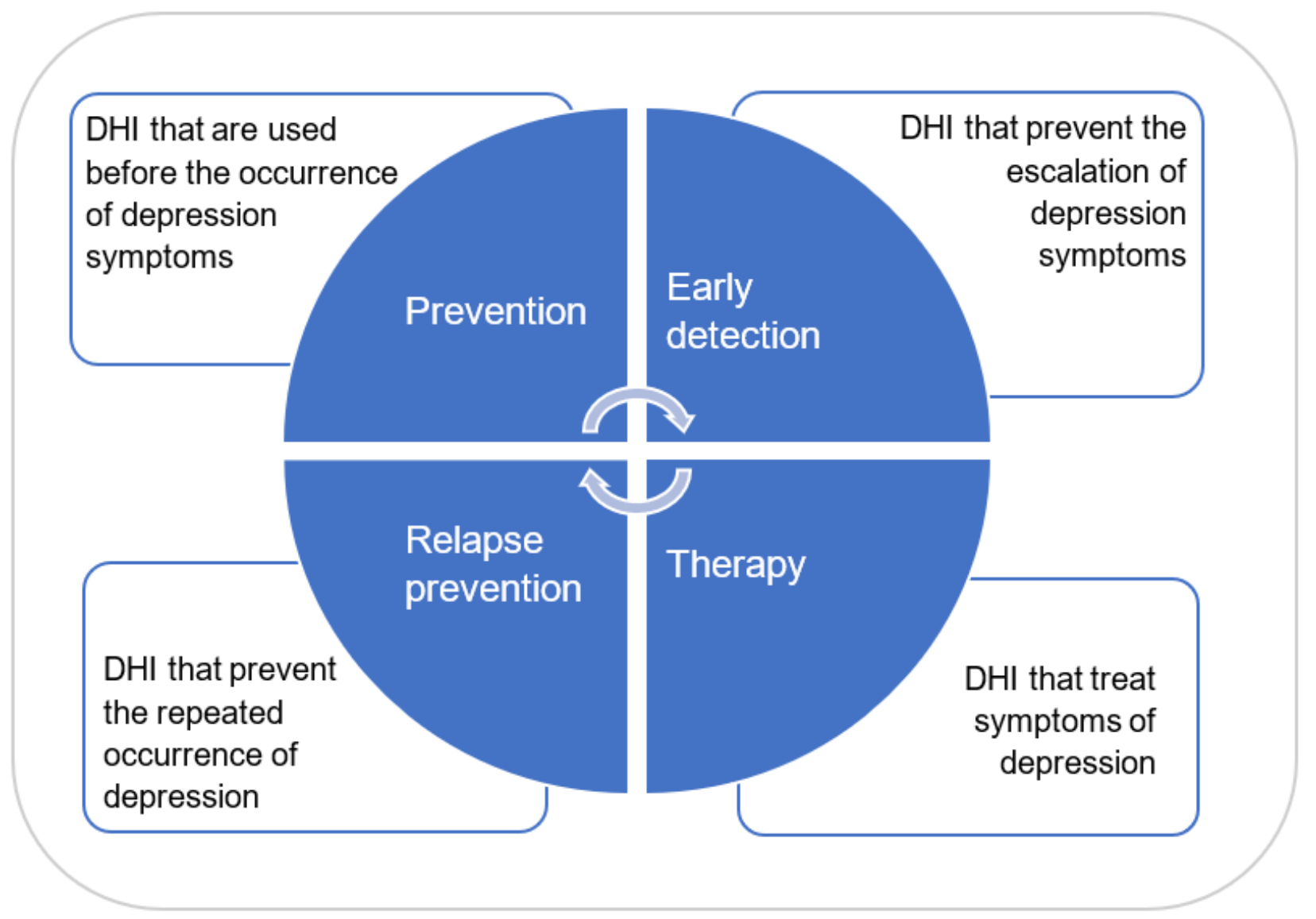

\section{Data Description: Prevention/Early Detection}

In the area of prevention, only one study was available in context of this scoping review [8]. The study was conducted in Germany and funded by the European Union (EU). Its duration was 6 weeks, with follow-ups after 6 months and 12 months. The study population consists of people with underlying depressive symptoms. Differentiation between an intervention group (IG) and control group (CG) was made ( $\mathrm{IG}=202$ and $\mathrm{CG}=204$; Multimedia Appendix 1).

The intervention GET.ON Mood Enhancer Prevention is a web-based guided self-help intervention based on psychoeducation, problem-solving therapy, and behavioral activation. The concepts were conveyed via multimodal and interactive elements in 6 sessions of about 30 minutes each with individual feedback by an online trainer. The $\mathrm{CG}$ received psychoeducation via the same web-based platform, but without the guidance of an online trainer. The primary outcome of the study was the diagnosis of major depression, which was recorded using the Diagnostic and Statistical Manual of Mental Disorders, Fifth Edition (DSM-5) criteria and a Structured Clinical Interview for DSM-5 (SCID).

Five studies were identified in the area of early detection (Multimedia Appendix 1). Two of the studies were conducted in Germany [9,10], 2 in the United States [11,12], and 1 in Romania [13]. Two studies were financed by the EU $[9,10]$, and 3 were funded by countries [11-13].
In all 5 studies, the study populations consisted of people with underlying depressive symptoms (ie, no manifest depressive disorder). In 4 studies, a differentiation was made between the IG and CG. The number of participants ranged from 35 to 202 in the IG (mean 102; mode 85.5) and from 36 to 204 participants in the CG (mean 93.7; mode 69). One study was a comparison of different interventions and did not have a CG [12]. The study periods ranged from 3 to 24 weeks.

Three out of the 5 studies chose a mixed form as treatment approach. In 2 studies, the intervention consisted of web-based cognitive behavioral therapy (CBT) and problem-solving therapy $[9,10]$. One study consisted of an app-based intervention based on CBT and problem-solving therapy, as well as an information control app [12]. In all 3 studies, the participants of the IG received support or reminder from an online trainer via a news system. Optionally, the participants could also choose to receive motivational text messages regularly to ensure continuity. In Place et al [11], the intervention consisted of a monitoring system that collected different types of metadata and clinicians providing feedback. In Buntrock et al [9], the CG only received psychoeducation through the web-based platform. In 2 studies, participants of the CG had unlimited access to treatment as usual (TAU) during the study period and were given access to the web-based intervention after the study period $[10,11]$.

The study by Tulbure et al [13] investigated a web-based transdiagnostic intervention. Thereby, therapy concepts of different mental diseases were transferred. In this study, 
concepts from the field of anxiety disorders were projected onto the field of depressive disorders. The IG received a web-based multimodal intervention in which additional writing tasks were completed. The participants could perform the intervention on a computer, tablet, or smartphone. Trained personnel monitored the activity of the participants. In addition, there was personalized feedback on writing tasks. Furthermore, participants received a reminder if inactivity was detected. No information was provided regarding the therapeutic approach. The CG received reading access to the platform [13].

All studies described depression-specific symptoms as primary outcome [9-13]. Additionally, in 2 studies, adherence to the intervention $[9,13]$ was indicated; in 1 study, quality of life [13] was.

\section{Data Description: Relapse Prevention}

In the area of relapse prevention, 4 studies from Germany [14-17], 1 study from the Netherlands [18], 1 study from Denmark [19], and 1 from the United States [20] were identified (Multimedia Appendix 1).

The study periods ranged from 4 weeks to 104 weeks (24 months). Four studies were financed by countries $[14,17,18,20]$, and 2 studies were privately financed [16,19]. One study did not provide information on financing [15]. Six studies differentiated between an IG and a CG [14-18,20]. The studies revealed large differences in sample size, ranging from 41 to 264 participants (mean 182; mode 217.5) when the IG and CG were combined. The sample sizes in the experimental arms of the studies varied between 21 and 230 participants (mean 115.2; mode 120). In the CG, the samples varied between 20 and 230 participants (mean 101.2; mode 91.5).

The interventions showed differences in their implementation. While almost all of them used a feedback function to indicate therapy success or remind patients to perform tasks, the therapy strategy differed. Four out of the 7 studies chose CBT as a therapeutic approach [16-18,20]. Some studies used CBT, either through a telerehabilitation program [16], mobile app [18], or web-based program [20]. Kraft et al [14] opted for a mindfulness-based exercise in which patients received feedback on the success via SMS. Lauritsen et al [19] used a web-based self-assessment tool that monitored participant mood, sleep, and activity, and Zwerenz et al [17] used a web-based self-help program based on CBT. One study did not provide any information on the chosen therapeutic approach [15]. Instead of the technical intervention, the CG of all studies received the nontechnical comparative therapy (ie, a comparable therapy) performed without the use of technical aid or TAU.

Five studies described depression-specific symptoms as primary outcome [15-17,19,20]. Additionally, adherence to the intervention $[14,19]$ and quality of life $[17,19]$ were indicated.

\section{Data Description: Therapy}

For the area of therapy, 52 studies were identified. A total of 12 studies were conducted in the United States [21-32], 6 studies in the Netherlands [33-38], and 11 in Germany [39-49]. Four studies were conducted in Australia [50-53]. Three studies were conducted in Switzerland [54-56] and 4 in Spain [57-60]. In
Canada [61,62], Finland [63,64], Sweden [65,66], and Great Britain [67,68] 2 studies each were identified. New Zealand [69], Austria [70], Ireland [71], and Japan [72] were each represented with 1 study (Multimedia Appendix 1).

Of those, 27 were sponsored by countries $[23,25,26,28-32,35,40,41,43,44,46,51,52,57-62,65,66,68,69,71]$ and 11 studies were privately financed $[24,33,34,36,37,48,49,53,55,56,67]$. The EU funded 2 studies $[39,42]$. One study indicated a mixture of private and state funding [21]. Eleven studies did not provide any information of financial sources $[22,27,38,45,47,50,54,63,64,70,72]$.

In the studies differentiating between an IG and CG, the number of participants ranged from 10 to 1904 participants in the IG (mean 191.0; mode 88) and from 8 to 1901 participants in the CG (mean 179.1; mode 67.5). The intervention periods of the studies ranged from 2 to 52 weeks (mean 11 weeks).

The majority of studies (41/52) differentiated between an IG and CG and were conducted as randomized controlled trials (RCTs) [22,24,27-29,33-52,54,55,57-61,63-69,71,72]. Seven studies were conducted as pilot studies [25,26,30-32,56,62]. Two studies had a quasi-experimental design $[23,70]$. One study was conducted as a usability study [53] and 1 as a controlled clinical trial [21].

\section{Technology Mapping: Therapy}

The therapy area yielded the largest number of studies. Therefore, the following technology mapping and analysis focus on therapeutic interventions for the reduction of depressive symptoms. In terms of therapeutic approach, CBT, acceptance and commitment therapy (ACT), and problem-solving therapy was considered because those are the most used approaches, and there was sufficient evidence to analyze. Studies were examined according to the type of technology used, medium used, and functions offered. Cross-references between the levels were drawn with the help of cross tables.

CBT was the dominant form of therapy in 54\% (28/52) of the studies [21,23,24,28,30,32,39-41,43-46,48-50,52,55-57,60-62, $65-67,70-72]$. In $19 \%$ (9/52), mixed forms were used, consisting of 2 or more forms of therapy [27,31,33,34,42,47,51,58,59]. Other therapy approaches such as ACT (5/52, 9\%) $[26,35,38,63,64]$ and problem-solving therapy $(4 / 52,8 \%)$ $[29,36,37,69]$ were significantly less common in interventions. The remaining studies either focused on cognitive restructuring [54], cognitive control therapy [22], behavioral activation $[45,68]$, or supplied no information about the therapeutic approach that was used [25].

Considering how therapy was technologically implemented, differences become apparent. Most of the studies (39/52, 75\%) used a web-based system in which an application was used online [21-23,28,33-46,48,49,52-55,57-67,69-72]. This form of therapy provision was the most common form. Mixed forms were also frequently used $(5 / 52,11 \%)$ using web-based and smartphone-based approaches [24,27,30,32,68]. Smartphone-based approaches were used by $12 \%(6 / 52)$ of studies $[25,26,31,47,50,56]$. One study $(2 \%)$ featuring problem-solving therapy used virtual reality for delivery, which 
entailed a virtual therapist giving instructions on skills in problem solving [29].

In addition, we analyzed which functions were integrated in the DHI. Multiple answers were possible, depending on which functions were given. Most of the DHIs (33/52, 63\%) were offered as guided interventions in which a therapist supported $\mathrm{t} h \mathrm{e} \quad \mathrm{p}$ a $\mathrm{r}$ t $\mathrm{i}$ c $\mathrm{i}$ p a $\mathrm{n}$ t $\mathrm{s}$ [21,25,26,28,29,31-39,42-44,47,49,54,55,57-60,62-64,67-71], with $15 \%(11 / 52)$ conducted as unguided interventions $[22,23,27,30,40,45,46,49,50,52,61]$ and $15 \%$ (11/52) using the reminder function to encourage patients to perform daily exercises or self-assessments [24,32,41,47,49,51,63-65,67,68]. While some studies $(6 / 52,8 \%)$ used tracking functions with biosensors [24,50,51,53,56,59], 3\% (2/52) used diary functions $[50,51]$ and $3 \%(2 / 52)$ used discussion forums [32,62]. A total of $9 \%(5 / 52)$ of studies used educational elements for the treatment of depression $[53,56,66,70,72]$.

\section{Evidence of DHI in Therapy for Depression}

A total of $71 \%(37 / 52)$ of studies reported improvements in d e p r e s s i v e $\mathrm{s}$ y $\mathrm{m} \mathrm{p} \mathrm{t} \mathrm{o} \mathrm{m} \mathrm{s}$ [22,30,32,37,40,42,44,46,49-51,53-57,59-64,67,68,70-72], 27\% (14/52) reported no (significant) effects $[21,31,33-36,41,45,47,48,58,65,66,69]$, and $2 \%(1 / 52)$ did not consider depressive symptoms as an outcome [52].

In Figure 3, the type of technology used with reported benefits of the studies is shown. In the case of web-based provision of DHIs, improvements of depressive symptoms becomes clear. A total of $67 \%(26 / 39)$ of studies identified a benefit $[22,23,28,37,40,42,44,46,49,52,55,57,59-64,67,70-72], \quad 31 \%$ (12/39) did not verify an improvement in depressive symptoms [21,33-36,41,45,48,58,65,66,69], and 1 study did not provide results for depressive outcomes [52]. All studies that used mixed forms of technology demonstrated a benefit. However, due to the small number of studies, this should be interpreted cautiously.

Figure 3. Evidence for digital health interventions classified by technology.

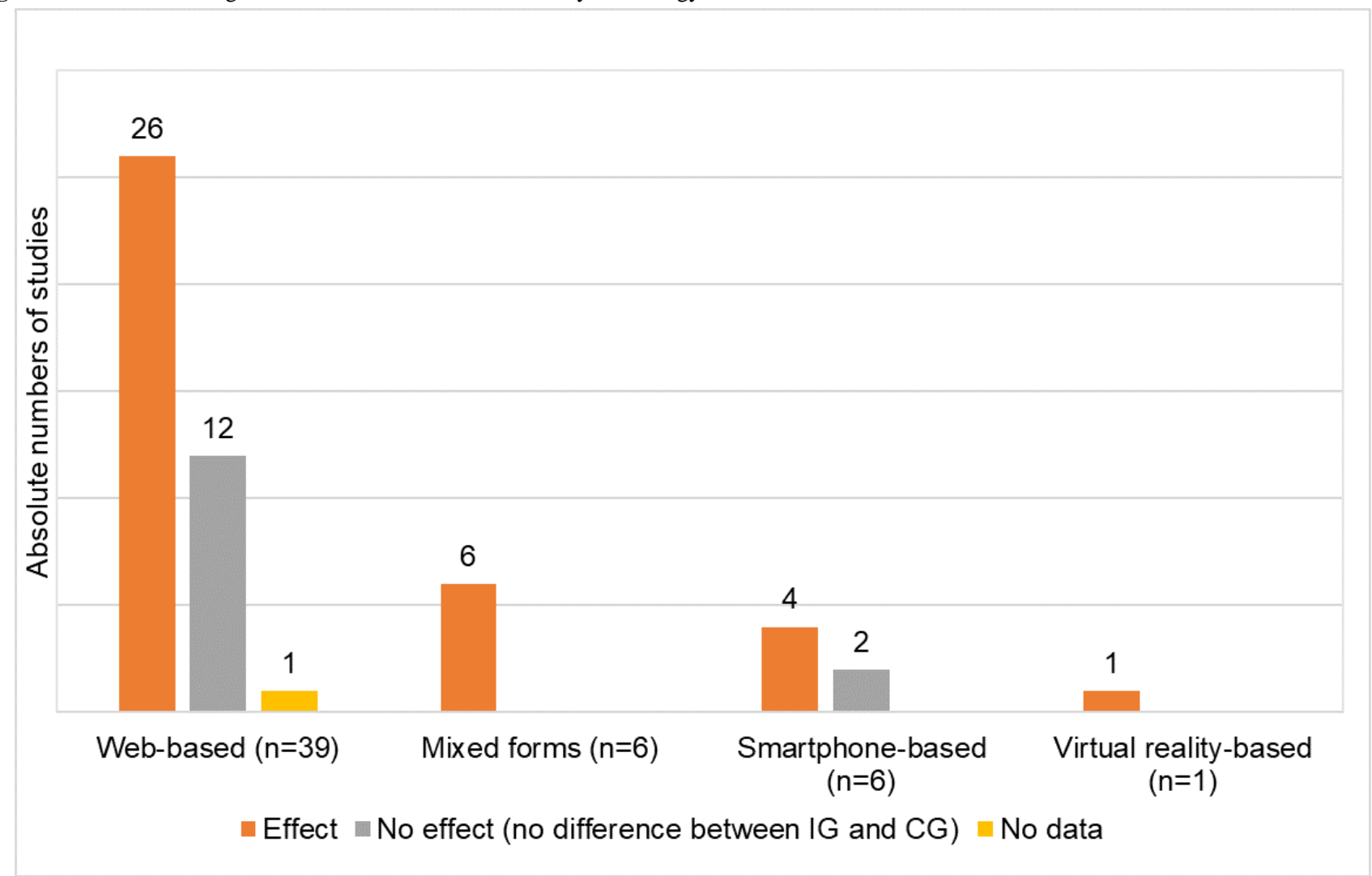

\section{Evidence for CBT}

In Figure 4, the therapy approach used with reported benefits is shown. A total of $75 \%(21 / 28)$ of studies that chose a CBT approach reported a positive effect on the reduction of $\mathrm{d}$ e p r e s s i v e s y m p t o m s $[23,24,28,30,32,39,40,44,46,49,50,55,57,60,62,67,70-72], 21 \%$ $(6 / 28)$ could not find any effect in terms of reduction $[21,41,43,47,65,66]$, and $4 \%(1 / 28)$ did not report any information on the depression outcome [52].
Of the studies with a positive effect, 76\% (16/21) were transmitted via web-based applications $[23,28,39,40,44,46,49,55,57,60-62,67,70-72], 48 \%$ (10/21) were designed as guided $[28,39,44,55,57,60,62,67,70,71]$ and $29 \%$ $(6 / 21)$ as unguided interventions [23,40,46,49,61,72].

In contrast, 6 studies could be identified that showed no or neutral results: 5 were web-based interventions $[21,41,43,65,66]$ and 1 study was designed as an app [47]. 
Figure 4. Evidence of digital health interventions classified by therapeutic approach.

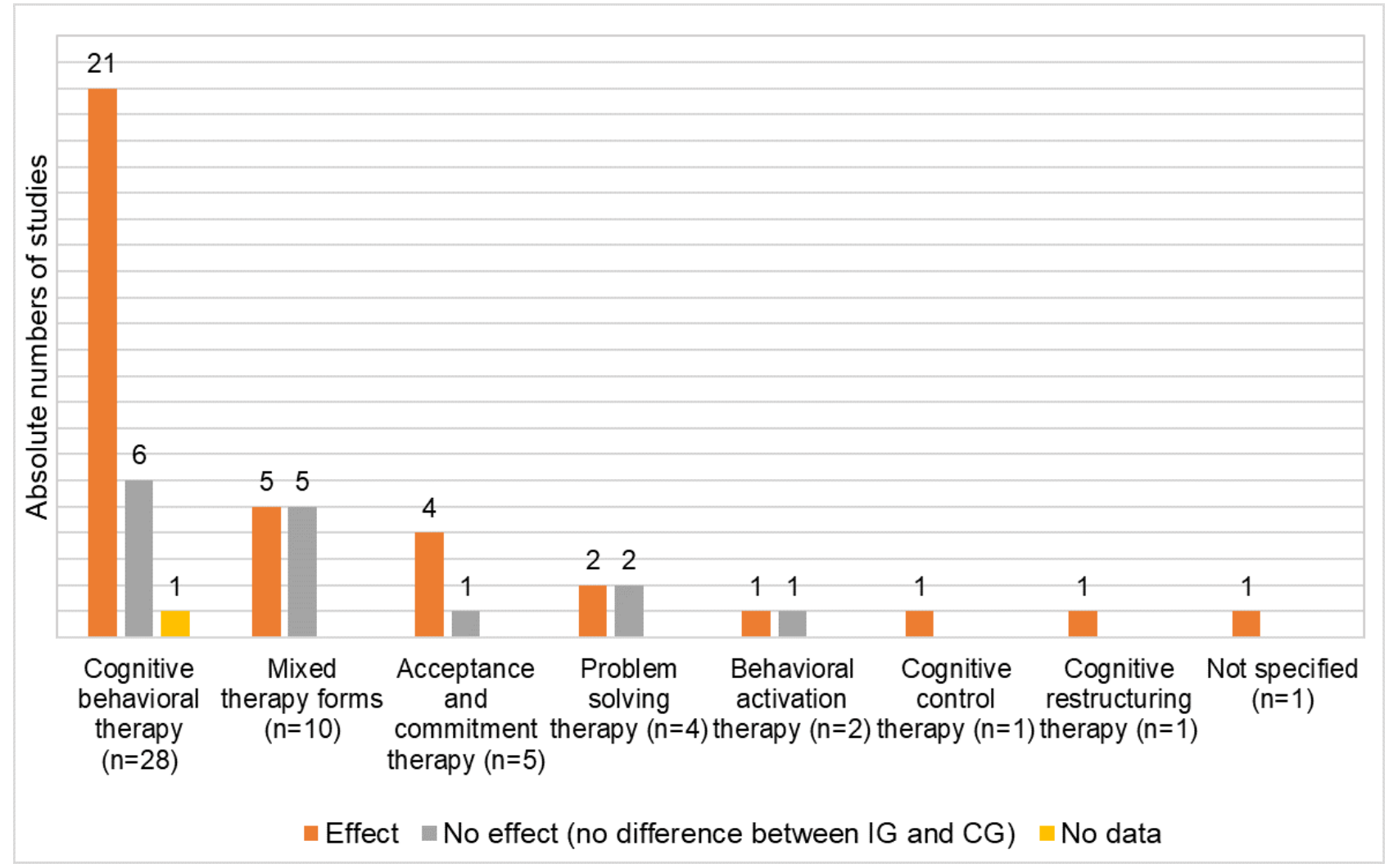

\section{Evidence for Problem-Solving Therapy}

The evidence for benefits using the problem-solving therapy approach is controversial. Of the studies identified, 50\% (2/4) determined a benefit in terms of an improvement in depressive symptoms [29,37] and 50\% (2/4) could not determine a difference between the IG and CG or simply do not represent significant improvement in the IG [36,69]. One of the studies with a reported benefit was a web-based application [37] and the second was a virtual reality intervention [29].

\section{Evidence for ACT}

Of the studies that chose ACT as a therapeutic approach, $80 \%$ (4/5) demonstrated a benefit regarding depressive symptoms $[26,38,63,64]$. One of the studies with a reported benefit was an app-based intervention [26] and 3 were designed as guided web-based interventions $[38,63]$. The study that did not indicate a benefit was a web-based intervention with automated feedback function [35].

\section{Discussion}

\section{Principal Findings}

The number of DHIs for treating depression is quite comprehensive. Focusing solely on therapeutic setting is not sufficient to show the different approaches of depression care. However, most of the studies were found in the therapy area. Of the 65 studies included, 52 focused on a therapy setting, 7 on relapse prevention, 5 on early detection, and 1 on the prevention of depression.

The most dominant approaches were CBT, ACT, and problem-solving therapy. Regarding the efficacy, most of the studies finding a benefit regarding symptom severity used CBT. Most studies found a significant effect of digital CBT for depression symptoms. Other studies not using DHIs for the provision of CBT have similar results for the efficacy of CBT regarding reduction of depression symptoms. Especially for mild and moderate depression, there is good evidence for symptom reduction [73]. Beyond that, the DHIs in most of the identified studies were realized through web-based technologies; mobile or smartphone-based interventions were still underrepresented.

Most of the included studies compared participants treated with DHIs with those not treated at all (eg, waitlist). In contrast, there were only a few studies that compared the efficacy of DHIs with traditional psychotherapy. It is not surprising that DHIs work better than no treatment at all. However, their efficacy is quite remarkable. Additionally, most studies were conducted under ideal controlled conditions, and studies investigating effectiveness in everyday life are still missing. For this reason, there are emerging discussions about adaptive study designs such as n-of- 1 or interrupted time-series designs, which can be better suited to evaluate DHIs. Although decision makers or payers still prefer RCTs as the gold standard for evidence, there are limitations when it comes to the measurement of efficacy and effectiveness for DHIs. Although health insurance companies offer their insureds DHIs, only $3 \%$ to $25 \%$ of patients take advantage of them [74]. Reasons for this are low expectations of their effectiveness, concerns about data security, poor user-friendliness, general skepticism about psychotherapy, and little experience with the internet in general [74]. 


\section{Comparison With Prior Work}

However, even for CBT, which is increasingly delivered by computerized forms, there is good evidence supporting the stated effects in this study. In the meta-analysis of Andersson and Cuijpers [75] that examined the effects of computerized CBT compared with face-to-face interventions, the authors found that computerized treatments do have promising potential for treating depression, and the computerized treatments were statistically significantly superior (posttest effect size: 0.41 , $95 \%$ CI $0.29-0.54, I^{2}=57 \%$ ) to face-to-face interventions.

The dissemination of technological systems poses a challenge for the field. DHIs developed within a research context vary in their implementation and technological approaches. Differences in technological attributes have been discussed in the literature. Studies have consistently demonstrated that effects appear to increase with higher levels of human guidance (eg, no guidance vs administrative guidance vs therapist guidance) $[4,76]$. Johansson et al [77] showed in a systematic review of 25 controlled trials that guided internet-based CBT is more effective than unguided internet-based CBT. Whereas the effect sizes in studies with people who had no therapist contact either before or during the treatment were relatively low (average effect size $d=0.21$ ), they improved with more support from the therapist. Studies with people who had contact with a therapist before and during the treatment reported a much higher average effect size $(d=0.76)$. Wright et al [78] showed similar results in a recent study from 2019. In a systematic review with 40 RCTs, they showed that studies providing support by a therapist or clinician yielded larger effects $(\mathrm{g}=0.67)$ than studies with unguided interventions $(g=0.24)$. One reason for this could be the missing therapeutic alliance was not compensated for with more content or technological support, apart from reminders. Therefore, it is possible that guidance becomes important, especially when systems are not very responsive.

Aside from this, there are many opportunities for DHIs in the treatment of depression. In fact, interventions are mostly delivered on the internet. Only a few publications considering mobile interventions were identified. This is surprising since smartphones are ubiquitous and highly prevalent nowadays. A review from 2015 identified 82 mobile apps for depression treatment [79]. Another review found that only 5 of those apps had been empirically evaluated in RCTs [80]. Regarding the high diffusion of commercially driven apps, scientifically evaluated apps are needed in future. In addition, innovative technologies using social media or virtual reality are underrepresented in this review.

\section{Limitations}

Most of the studies were found in the area of therapy. One reason for this could be that preventive offers are not recognized the way therapeutic interventions are, even if those preventive interventions are advisable due to individual risk factors. It could be helpful to provide a wider range of preventive services and a larger number of psychotherapists as well as general practitioners to give their patients recommendations for preventive interventions.

All studies tried to determine the effects of depression-specific symptoms, but in doing so the authors of the studies used different instruments. While some researchers used the Center for Epidemiological Studies Depression Scale or the Quick Inventory of Depressive Symptomatology-16 item scale, the Patient Health Questionnaire-9 Item and Beck Depression Inventory II scales were most commonly used. Because of this heterogeneity, there is a limitation considering the comparability of studies.

A limitation concerns the scope of the reviewed publications. Systems developed for children and adolescents and women with postpartum depression and studies published before 2010 were excluded. Therefore, it is necessary to investigate in further research if the findings can be generalized to those types of systems. As data security is an important concern of DHIs, consistent guidelines and criteria for future systems are needed. Despite these limitations, the findings of our analysis highlight some of the challenges and opportunities for the use of DHIs for depression.

\section{Conclusion}

The aim of this scoping review was to approach the state of DHIs for mild and moderate depression and try to describe those interventions for depression care. It is known that DHIs have great potential to complement the treatment of depressive people and intensify traditional psychotherapy. This review indicates DHIs also show great potential in avoiding depression (prevention and early detection) and preventing relapse, which is currently underrepresented in the literature. The field of DHIs is constantly increasing, and there is no general evidence of the effect of these interventions, but most of the studies included in this review improved the effects of DHIs for the reduction of depressive symptoms. Furthermore, results showed that most of the DHIs provided web-based CBT and a combination of several technological options (eg, reminder, tracking). Even with automated programs and contact with psychotherapists (eg, contact through chats or email), people show great improvement in their symptoms in comparison to interventions without support at all. It appears to be crucial for people to have professional guidance. Further research is needed to investigate whether more technologically advanced systems lead to higher adherence and effects for the reduction of depressive symptoms in addition to investigating real-world effectiveness and barriers for implementation of DHIs.

\section{Acknowledgments}

We acknowledge support for the publication costs from the Deutsche Forschungsgemeinschaft and the Open Access Publication Fund of Bielefeld University. This project was financially supported by a grant from the Landeszentrum Gesundheit North Rhine-Westphalia (LZG.NRW), a professional and state-run coordination center for public health services in North Rhine-Westphalia within the portfolio of the Ministry of Labour, Health, and Social Affairs of North Rhine-Westphalia that gives support and expert advice in all health issues to the authorities in the government and municipalities. The LZG.NRW played no 
role in the planning and conceptualization of the manuscript, did not participate in the writing of the manuscript, and played no role in the decision to submit the manuscript.

\section{Authors' Contributions}

PT, RH, JH, SS, and CD were involved and contributed at each step of manuscript writing. All the authors read and approved the final manuscript.

\section{Conflicts of Interest}

None declared.

\section{Multimedia Appendix 1}

Study characteristics of the included studies. [DOCX File, 58 KB-Multimedia Appendix 1]

\section{References}

1. Herrman H, Kieling C, McGorry P, Horton R, Sargent J, Patel V. Reducing the global burden of depression: a Lancet-World Psychiatric Association Commission. Lancet 2019 Jun 15;393(10189):e42-e43. [doi: 10.1016/S0140-6736(18)32408-5] [Medline: $\underline{30482607]}$

2. Rycroft-Malone J, Gradinger F, Owen Griffiths H, Anderson R, Crane RS, Gibson A, et al. "Mind the gaps": the accessibility and implementation of an effective depression relapse prevention programme in UK NHS services: learning from mindfulness-based cognitive therapy through a mixed-methods study. BMJ Open 2019 Sep 08;9(9):e026244 [FREE Full text] [doi: 10.1136/bmjopen-2018-026244] [Medline: $\underline{31501097]}$

3. Andersson G, Titov N. Advantages and limitations of Internet-based interventions for common mental disorders. World Psychiatry 2014 Feb;13(1):4-11 [FREE Full text] [doi: 10.1002/wps.20083] [Medline: 24497236]

4. Richards D, Richardson T. Computer-based psychological treatments for depression: a systematic review and meta-analysis. Clin Psychol Rev 2012 Jun;32(4):329-342. [doi: 10.1016/j.cpr.2012.02.004] [Medline: 22466510]

5. Arksey H, O'Malley L. Scoping studies: towards a methodological framework. Int J Soc Res Methodol 2005 Feb;8(1):19-32. [doi: 10.1080/1364557032000119616]

6. Tricco AC, Lillie E, Zarin W, O'Brien K, Colquhoun H, Kastner M, et al. A scoping review on the conduct and reporting of scoping reviews. BMC Med Res Methodol 2016 Feb 09;16:15 [FREE Full text] [doi: 10.1186/s12874-016-0116-4] [Medline: 26857112]

7. Moher D, Liberati A, Tetzlaff J, Altman DG. Preferred reporting items for systematic reviews and meta-analyses: the PRISMA statement. PLoS Med 2009 Jul 21;6(7):e1000097 [FREE Full text] [doi: 10.1371/journal.pmed.1000097] [Medline: 19621072]

8. Buntrock C, Ebert DD, Lehr D, Smit F, Riper H, Berking M, et al. Effect of a web-based guided self-help intervention for prevention of major depression in adults with subthreshold depression: a randomized clinical trial. JAMA 2016 May 3;315(17):1854-1863. [doi: 10.1001/jama.2016.4326] [Medline: 27139058]

9. Buntrock C, Ebert D, Lehr D, Riper H, Smit F, Cuijpers P, et al. Effectiveness of a web-based cognitive behavioural intervention for subthreshold depression: pragmatic randomised controlled trial. Psychother Psychosom 2015;84(6):348-358. [doi: 10.1159/000438673] [Medline: 26398885]

10. Ebert DD, Buntrock C, Lehr D, Smit F, Riper H, Baumeister H, et al. Effectiveness of web- and mobile-based treatment of subthreshold depression with adherence-focused guidance: a single-blind randomized controlled trial. Behav Ther 2018 Dec;49(1):71-83. [doi: 10.1016/j.beth.2017.05.004] [Medline: 29405923]

11. Place S, Blanch-Hartigan D, Smith V, Erb J, Marci CD, Ahern DK. Effect of a mobile monitoring system vs usual care on depression symptoms and psychological health: a randomized clinical trial. JAMA Netw Open 2020 Jan 03;3(1):e1919403 [FREE Full text] [doi: 10.1001/jamanetworkopen.2019.19403] [Medline: 31951270]

12. Pratap A, Renn BN, Volponi J, Mooney SD, Gazzaley A, Arean PA, et al. Using mobile apps to assess and treat depression in Hispanic and Latino populations: fully remote randomized clinical trial. J Med Internet Res 2018 Aug 09;20(8):e10130 [FREE Full text] [doi: 10.2196/10130] [Medline: 30093372]

13. Tulbure BT, Rusu A, Sava FA, Sălăgean N, Farchione TJ. A web-based transdiagnostic intervention for affective and mood disorders: randomized controlled trial. JMIR Ment Health 2018 May 24;5(2):e36 [FREE Full text] [doi: 10.2196/mental.8901] [Medline: 29798831]

14. Kraft S, Wolf M, Klein T, Becker T, Bauer S, Puschner B. Text message feedback to support mindfulness practice in people with depressive symptoms: a pilot randomized controlled trial. JMIR Mhealth Uhealth 2017 May 02;5(5):e59 [FEE Full text] [doi: 10.2196/mhealth.7095] [Medline: 28465278] 
15. Schlicker S, Ebert DD, Middendorf T, Titzler I, Berking M. Evaluation of a text-message-based maintenance intervention for Major Depressive Disorder after inpatient cognitive behavioral therapy. J Affect Disord 2018 Feb;227:305-312. [doi: 10.1016/j.jad.2017.10.047] [Medline: 29132073]

16. Schmadeke S, Bischoff C. Effects of smartphone-supported rehabilitation aftercare (eATROS) for depressive patients. Verhaltenstherapie 2015 Nov 23;25(4):277-286. [doi: 10.1159/000441856]

17. Zwerenz R, Baumgarten C, Becker J, Tibubos A, Siepmann M, Knickenberg RJ, et al. Improving the course of depressive symptoms after inpatient psychotherapy using adjunct web-based self-help: follow-up results of a randomized controlled trial. J Med Internet Res 2019 Oct 24;21(10):e13655 [FREE Full text] [doi: 10.2196/13655] [Medline: $\underline{31651403]}$

18. Klein NS, Bockting CL, Wijnen B, Kok GD, van Valen E, Riper H, et al. Economic evaluation of an internet-based preventive cognitive therapy with minimal therapist support for recurrent depression: randomized controlled trial. J Med Internet Res 2018 Dec 26;20(11):e10437 [FREE Full text] [doi: 10.2196/10437] [Medline: 30478021]

19. Lauritsen L, Andersen L, Olsson E, Søndergaard SR, Nørregaard LB, Løventoft PK, et al. Usability, acceptability, and adherence to an electronic self-monitoring system in patients with major depression discharged from inpatient wards. J Med Internet Res 2017 Dec 21;19(4):e123 [FREE Full text] [doi: 10.2196/jmir.6673] [Medline: 28432040]

20. Segal ZV, Dimidjian S, Beck A, Boggs JM, Vanderkruik R, Metcalf CA, et al. Outcomes of online mindfulness-based cognitive therapy for patients with residual depressive symptoms: a randomized clinical trial. JAMA Psychiatry 2020 Jun 01;77(6):563-573. [doi: 10.1001/jamapsychiatry.2019.4693] [Medline: 31995132]

21. Aguilera A, Bruehlman-Senecal E, Demasi O, Avila P. Automated text messaging as an adjunct to cognitive behavioral therapy for depression: a clinical trial. J Med Internet Res 2017 May 08;19(5):e148 [FREE Full text] [doi: 10.2196/jmir.6914] [Medline: 28483742]

22. Calkins AW, McMorran KE, Siegle GJ, Otto MW. The effects of computerized cognitive control training on community adults with depressed mood. Behav Cogn Psychother 2015 Sep;43(5):578-589. [doi: 10.1017/S1352465814000046] [Medline: 24589123]

23. Dimidjian S, Beck A, Felder JN, Boggs JM, Gallop R, Segal ZV. Web-based mindfulness-based cognitive therapy for reducing residual depressive symptoms: an open trial and quasi-experimental comparison to propensity score matched controls. Behav Res Ther 2014 Dec;63:83-89. [doi: 10.1016/j.brat.2014.09.004] [Medline: 25461782]

24. Hirsch A, Luellen J, Holder JM, Steinberg G, Dubiel T, Blazejowskyj A, et al. Managing depressive symptoms in the workplace using a web-based self-care tool: a pilot randomized controlled trial. JMIR Res Protoc 2017 Apr 04;6(4):e51 [FREE Full text] [doi: 10.2196/resprot.7203] [Medline: 28377368]

25. Mohr DC, Tomasino KN, Lattie EG, Palac HL, Kwasny MJ, Weingardt K, et al. IntelliCare: an eclectic, skills-based app suite for the treatment of depression and anxiety. J Med Internet Res 2017 Jan 05;19(1):e10 [FREE Full text] [doi: 10.2196/jmir.6645] [Medline: 28057609]

26. Pfeiffer PN, Henry J, Ganoczy D, Piette JD. Pilot study of psychotherapeutic text messaging for depression. J Telemed Telecare 2017 Aug;23(7):665-672. [doi: 10.1177/1357633X16659955] [Medline: 27450571]

27. Roepke AM, Jaffee SR, Riffle OM, McGonigal J, Broome R, Maxwell B. Randomized controlled trial of superbetter, a smartphone-based/internet-based self-help tool to reduce depressive symptoms. Games Health J 2015 Jun;4(3):235-246. [doi: $10.1089 / \mathrm{g} 4 \mathrm{~h} .2014 .0046]$ [Medline: 26182069]

28. Rosso IM, Killgore WDS, Olson EA, Webb CA, Fukunaga R, Auerbach RP, et al. Internet-based cognitive behavior therapy for major depressive disorder: a randomized controlled trial. Depress Anxiety 2017 Mar;34(3):236-245 [FREE Full text] [doi: 10.1002/da.22590] [Medline: 28009467]

29. Sandoval LR, Buckey JC, Ainslie R, Tombari M, Stone W, Hegel MT. Randomized controlled trial of a computerized interactive media-based problem solving treatment for depression. Behav Ther 2017 May;48(3):413-425 [FREE Full text] [doi: 10.1016/j.beth.2016.04.001] [Medline: 28390503]

30. Schure MB, Lindow JC, Greist JH, Nakonezny PA, Bailey SJ, Bryan WL, et al. Use of a fully automated internet-based cognitive behavior therapy intervention in a community population of adults with depression symptoms: randomized controlled trial. J Med Internet Res 2019 Nov 18;21(11):e14754 [FREE Full text] [doi: 10.2196/14754] [Medline: 31738173]

31. Stiles-Shields C, Montague E, Kwasny MJ, Mohr DC. Behavioral and cognitive intervention strategies delivered via coached apps for depression: pilot trial. Psychol Serv 2019 May;16(2):233-238. [doi: 10.1037/ser0000261] [Medline: 30407055]

32. Tomasino KN, Lattie EG, Ho J, Palac HL, Kaiser SM, Mohr DC. Harnessing peer support in an online intervention for older adults with depression. Am J Geriatr Psychiatry 2017 Oct;25(10):1109-1119. [doi: 10.1016/j.jagp.2017.04.015] [Medline: 28571785]

33. Geraedts AS, Kleiboer AM, Twisk J, Wiezer NM, van Mechelen W, Cuijpers P. Long-term results of a web-based guided self-help intervention for employees with depressive symptoms: randomized controlled trial. J Med Internet Res 2014;16(7):e168 [FREE Full text] [doi: 10.2196/jmir.3539] [Medline: 25008127]

34. Geraedts AS, van Dongen JM, Kleiboer AM, Wiezer NM, van Mechelen W, Cuijpers P, et al. Economic evaluation of a web-based guided self-help intervention for employees with depressive symptoms: results of a randomized controlled trial. J Occup Environ Med 2015 Jun;57(6):666-675. [doi: 10.1097/JOM.0000000000000423] [Medline: 25741795] 
35. Kelders SM, Bohlmeijer ET, Pots WTM, van Gemert-Pijnen EWC. Comparing human and automated support for depression: fractional factorial randomized controlled trial. Behav Res Ther 2015 Sep;72:72-80. [doi: 10.1016/j.brat.2015.06.014] [Medline: 26196078]

36. Kenter RMF, Cuijpers P, Beekman A, van Straten A. Effectiveness of a web-based guided self-help intervention for outpatients with a depressive disorder: short-term results from a randomized controlled trial. J Med Internet Res 2016 Mar 31;18(3):e80 [FREE Full text] [doi: 10.2196/jmir.4861] [Medline: 27032449]

37. Kleiboer A, Donker T, Seekles W, van Straten A, Riper H, Cuijpers P. A randomized controlled trial on the role of support in Internet-based problem solving therapy for depression and anxiety. Behav Res Ther 2015 Sep;72:63-71. [doi: 10.1016/j.brat.2015.06.013] [Medline: 26188373]

38. Pots WTM, Fledderus M, Meulenbeek PAM, ten Klooster PM, Schreurs KMG, Bohlmeijer ET. Acceptance and commitment therapy as a web-based intervention for depressive symptoms: randomised controlled trial. Br J Psychiatry 2016 Jan;208(1):69-77. [doi: 10.1192/bjp.bp.114.146068] [Medline: 26250745]

39. Beiwinkel T, Eißing T, Telle N, Siegmund-Schultze E, Rössler W. Effectiveness of a web-based intervention in reducing depression and sickness absence: randomized controlled trial. J Med Internet Res 2017 Jun 15;19(6):e213 [FREE Full text] [doi: 10.2196/jmir.6546] [Medline: 28619701]

40. Berger T, Krieger T, Sude K, Meyer B, Maercker A. Evaluating an e-mental health program ("deprexis") as adjunctive treatment tool in psychotherapy for depression: results of a pragmatic randomized controlled trial. J Affect Disord 2018 Feb;227:455-462. [doi: 10.1016/j.jad.2017.11.021] [Medline: 29154168]

41. Bücker L, Schnakenberg P, Karyotaki E, Moritz S, Westermann S. Diminishing effects after recurrent use of self-guided internet-based interventions in depression: randomized controlled trial. J Med Internet Res 2019 Oct 02;21(10):e14240 [FREE Full text] [doi: 10.2196/14240] [Medline: 31579014]

42. Ebert DD, Buntrock C, Lehr D, Smit F, Riper H, Baumeister H, et al. Effectiveness of web- and mobile-based treatment of subthreshold depression with adherence-focused guidance: a single-blind randomized controlled trial. Behav Ther 2018 Dec;49(1):71-83. [doi: 10.1016/j.beth.2017.05.004] [Medline: 29405923]

43. Gräfe V, Berger T, Hautzinger M, Hohagen F, Lutz W, Meyer B, et al. Health economic evaluation of a web-based intervention for depression: the EVIDENT-trial, a randomized controlled study. Health Econ Rev 2019 Jun 07;9(1):16 [FREE Full text] [doi: $10.1186 / \mathrm{s} 13561-019-0233-\mathrm{y}$ ] [Medline: $\underline{31175475]}$

44. Gräfe V, Moritz S, Greiner W. Health economic evaluation of an internet intervention for depression (deprexis), a randomized controlled trial. Health Econ Rev 2020 Jun 16;10(1):19 [FREE Full text] [doi: 10.1186/s13561-020-00273-0] [Medline: 32548724]

45. Jelinek L, Arlt S, Moritz S, Schröder J, Westermann S, Cludius B. Brief web-based intervention for depression: randomized controlled trial on behavioral activation. J Med Internet Res 2020 Mar 26;22(3):e15312 [FREE Full text] [doi: 10.2196/15312] [Medline: $\underline{\text { 32213470] }}$

46. Löbner M, Dorow M, Pabst A, Stein J, Kersting A, Luppa M, et al. [Online self-management of depression: dose-response-relationship within a primary care setting]. Fortschr Neurol Psychiatr 2019 Mar;87(3):181-186. [doi: 10.1055/a-0849-9802] [Medline: $\underline{30891721]}$

47. Lüdtke T, Pult LK, Schröder J, Moritz S, Bücker L. A randomized controlled trial on a smartphone self-help application (Be Good to Yourself) to reduce depressive symptoms. Psychiatry Res 2018 Nov;269:753-762. [doi: 10.1016/j.psychres.2018.08.113] [Medline: 30273901]

48. Zagorscak P, Heinrich M, Bohn J, Stein J, Knaevelsrud C. How individuals change during internet-based interventions for depression: a randomized controlled trial comparing standardized and individualized feedback. Brain Behav 2020 Jan;10(1):e01484 [FREE Full text] [doi: 10.1002/brb3.1484] [Medline: 31777204]

49. Zwerenz R, Becker J, Johansson R, Frederick RJ, Andersson G, Beutel ME. Transdiagnostic, psychodynamic web-based self-help intervention following inpatient psychotherapy: results of a feasibility study and randomized controlled trial. JMIR Ment Health 2017 Oct 16;4(4):e41 [FREE Full text] [doi: 10.2196/mental.7889] [Medline: 29038094]

50. Bakker D, Kazantzis N, Rickwood D, Rickard N. A randomized controlled trial of three smartphone apps for enhancing public mental health. Behav Res Ther 2018 Oct;109:75-83. [doi: 10.1016/j.brat.2018.08.003] [Medline: $\underline{30125790]}$

51. Clarke J, Proudfoot J, Birch M, Whitton AE, Parker G, Manicavasagar V, et al. Effects of mental health self-efficacy on outcomes of a mobile phone and web intervention for mild-to-moderate depression, anxiety and stress: secondary analysis of a randomised controlled trial. BMC Psychiatry 2014; 14:272 [FREE Full text] [doi: 10.1186/s12888-014-0272-1] [Medline: 25252853]

52. Crisp D, Griffiths K, Mackinnon A, Bennett K, Christensen H. An online intervention for reducing depressive symptoms: secondary benefits for self-esteem, empowerment and quality of life. Psychiatry Res 2014 Apr 30;216(1):60-66. [doi: 10.1016/j.psychres.2014.01.041] [Medline: 24534125]

53. Fogarty AS, Proudfoot J, Whittle EL, Clarke J, Player MJ, Christensen H, et al. Preliminary evaluation of a brief web and mobile phone intervention for men with depression: men's positive coping strategies and associated depression, resilience, and work and social functioning. JMIR Ment Health 2017 Aug 10;4(3):e33 [FREE Full text] [doi: 10.2196/mental.7769] [Medline: 28798009] 
54. Pictet A, Jermann F, Ceschi G. When less could be more: investigating the effects of a brief internet-based imagery cognitive bias modification intervention in depression. Behav Res Ther 2016 Dec;84:45-51. [doi: 10.1016/j.brat.2016.07.008] [Medline: 27485252]

55. Wagner B, Horn AB, Maercker A. Internet-based versus face-to-face cognitive-behavioral intervention for depression: a randomized controlled non-inferiority trial. J Affect Disord 2014 Jan;152-154:113-121. [doi: 10.1016/j.jad.2013.06.032] [Medline: 23886401]

56. Wahle F, Kowatsch T, Fleisch E, Rufer M, Weidt S. Mobile sensing and support for people with depression: a pilot trial in the wild. JMIR Mhealth Uhealth 2016 Sep 21;4(3):e111 [FREE Full text] [doi: 10.2196/mhealth.5960] [Medline: 27655245]

57. Castro A, García-Palacios A, López-Del-Hoyo Y, Mayoral F, Pérez-Ara, Baños RM, et al. Predictors of adherence in three low-intensity intervention programs applied by ICTs for depression in primary care. Int J Environ Res Public Health 2021 Feb 11;18(4):246-261 [FREE Full text] [doi: 10.3390/ijerph18041774] [Medline: 33670353]

58. Gili M, Castro A, García-Palacios A, Garcia-Campayo J, Mayoral-Cleries F, Botella C, et al. Efficacy of three low-intensity, internet-based psychological interventions for the treatment of depression in primary care: randomized controlled trial. $\mathbf{J}$ Med Internet Res 2020 Jun 05;22(6):e15845 [FREE Full text] [doi: 10.2196/15845] [Medline: 32501276]

59. Mira A, Bretón-López J, García-Palacios A, Quero S, Baños RM, Botella C. An Internet-based program for depressive symptoms using human and automated support: a randomized controlled trial. Neuropsychiatr Dis Treat 2017;13:987-1006 [FREE Full text] [doi: 10.2147/NDT.S130994] [Medline: 28408833]

60. Mira A, Bretón-López J, Enrique A, Castilla D, García-Palacios A, Baños R, et al. Exploring the incorporation of a positive psychology component in a cognitive behavioral internet-based program for depressive symptoms. results throughout the intervention process. Front Psychol 2018;9:2360 [FREE Full text] [doi: 10.3389/fpsyg.2018.02360] [Medline: 30555384]

61. Agyapong VIO, Juhás M, Ohinmaa A, Omeje J, Mrklas K, Suen VYM, et al. Randomized controlled pilot trial of supportive text messages for patients with depression. BMC Psychiatry 2017 Aug 02;17(1):286 [FREE Full text] [doi:

10.1186/s12888-017-1448-2] [Medline: 28768493]

62. Khatri N, Marziali E, Tchernikov I, Shepherd N. Comparing telehealth-based and clinic-based group cognitive behavioral therapy for adults with depression and anxiety: a pilot study. Clin Interv Aging 2014;9:765-770 [FREE Full text] [doi: 10.2147/CIA.S57832] [Medline: 24855345]

63. Lappalainen P, Granlund A, Siltanen S, Ahonen S, Vitikainen M, Tolvanen A, et al. ACT Internet-based vs face-to-face? A randomized controlled trial of two ways to deliver Acceptance and Commitment Therapy for depressive symptoms: an 18-month follow-up. Behav Res Ther 2014 Oct;61:43-54. [doi: 10.1016/j.brat.2014.07.006] [Medline: 25127179]

64. Lappalainen P, Langrial S, Oinas-Kukkonen H, Tolvanen A, Lappalainen R. Web-based acceptance and commitment therapy for depressive symptoms with minimal support: a randomized controlled trial. Behav Modif 2015 Aug 6;39(6):805-834. [doi: 10.1177/0145445515598142] [Medline: 26253644]

65. Flygare A, Engström I, Hasselgren M, Jansson-Fröjmark M, Frejgrim R, Andersson G, et al. Internet-based CBT for patients with depressive disorders in primary and psychiatric care: is it effective and does comorbidity affect outcome? Internet Interv 2020 Mar;19:100303 [FREE Full text] [doi: 10.1016/j.invent.2019.100303] [Medline: 32055451$]$

66. Kivi M, Eriksson MCM, Hange D, Petersson E, Vernmark K, Johansson B, et al. Internet-based therapy for mild to moderate depression in Swedish primary care: short term results from the PRIM-NET randomized controlled trial. Cogn Behav Ther 2014;43(4):289-298 [FREE Full text] [doi: 10.1080/16506073.2014.921834] [Medline: 24911260]

67. Blackwell SE, Browning M, Mathews A, Pictet A, Welch J, Davies J, et al. Positive imagery-based cognitive bias modification as a web-based treatment tool for depressed adults: a randomized controlled trial. Clin Psychol Sci 2015 Jan;3(1):91-111 [FREE Full text] [doi: 10.1177/2167702614560746] [Medline: 25984421]

68. Lambert JD, Greaves CJ, Farrand P, Price L, Haase AM, Taylor AH. Web-based intervention using behavioral activation and physical activity for adults with depression (The eMotion Study): pilot randomized controlled trial. J Med Internet Res 2018 Jul 16;20(7):e10112 [FREE Full text] [doi: 10.2196/10112] [Medline: 30012547]

69. Hatcher S, Whittaker R, Patton M, Miles WS, Ralph N, Kercher K, et al. Web-based therapy plus support by a coach in depressed patients referred to secondary mental health care: randomized controlled trial. JMIR Ment Health 2018 Jan 23;5(1):e5 [FREE Full text] [doi: 10.2196/mental.8510] [Medline: 29362207]

70. Schuster R, Fichtenbauer I, Sparr VM, Berger T, Laireiter A. Feasibility of a blended group treatment (bGT) for major depression: uncontrolled interventional study in a university setting. BMJ Open 2018 Mar 12;8(3):e018412 [FREE Full text] [doi: 10.1136/bmjopen-2017-018412] [Medline: 29530905]

71. Richards D, Timulak L, O'Brien E, Hayes C, Vigano N, Sharry J, et al. A randomized controlled trial of an internet-delivered treatment: its potential as a low-intensity community intervention for adults with symptoms of depression. Behav Res Ther 2015 Dec;75:20-31 [FREE Full text] [doi: 10.1016/j.brat.2015.10.005] [Medline: 26523885]

72. Imamura K, Kawakami N, Tsuno K, Tsuchiya M, Shimada K, Namba K. Effects of web-based stress and depression literacy intervention on improving symptoms and knowledge of depression among workers: a randomized controlled trial. J Affect Disord 2016 Oct;203:30-37. [doi: 10.1016/j.jad.2016.05.045] [Medline: 27280960] 
73. Barth J, Munder T, Gerger H, Nüesch E, Trelle S, Znoj H, et al. Comparative efficacy of seven psychotherapeutic interventions for patients with depression: a network meta-analysis. PLoS Med 2013;10(5):e1001454 [FREE Full text] [doi: 10.1371/journal.pmed.1001454] [Medline: 23723742]

74. Ebert DD, Berking M, Cuijpers P, Lehr D, Pörtner M, Baumeister H. Increasing the acceptance of internet-based mental health interventions in primary care patients with depressive symptoms: a randomized controlled trial. J Affect Disord 2015 May 1;176:9-17. [doi: 10.1016/j.jad.2015.01.056] [Medline: 25682378]

75. Andersson G, Cuijpers P. Internet-based and other computerized psychological treatments for adult depression: a meta-analysis. Cogn Behav Ther 2009;38(4):196-205. [doi: 10.1080/16506070903318960] [Medline: 20183695]

76. Andersson G, Cuijpers P, Carlbring P, Riper H, Hedman E. Guided Internet-based vs. face-to-face cognitive behavior therapy for psychiatric and somatic disorders: a systematic review and meta-analysis. World Psychiatry 2014 Oct;13(3):288-295 [FREE Full text] [doi: 10.1002/wps.20151] [Medline: 25273302]

77. Johansson R, Andersson G. Internet-based psychological treatments for depression. Expert Rev Neurother 2012 Jul;12(7):861-869. [doi: 10.1586/ern.12.63] [Medline: 22853793]

78. Wright JH, Mishkind M, Eells TD, Chan SR. Computer-assisted cognitive-behavior therapy and mobile apps for depression and anxiety. Curr Psychiatry Rep 2019 Jun 27;21(7):62. [doi: 10.1007/s11920-019-1031-2] [Medline: 31250242]

79. Shen N, Levitan M, Johnson A, Bender JL, Hamilton-Page M, Jadad AAR, et al. Finding a depression app: a review and content analysis of the depression app marketplace. JMIR Mhealth Uhealth 2015;3(1):e16 [FREE Full text] [doi: 10.2196/mhealth.3713] [Medline: 25689790]

80. Van Ameringen M, Turna J, Khalesi Z, Pullia K, Patterson B. There is an app for that! The current state of mobile applications (apps) for DSM-5 obsessive-compulsive disorder, posttraumatic stress disorder, anxiety and mood disorders. Depress Anxiety 2017 Jun;34(6):526-539. [doi: 10.1002/da.22657] [Medline: 28569409]

\author{
Abbreviations \\ ACT: acceptance and commitment therapy \\ CBT: cognitive behavioral therapy \\ CG: control group \\ DHI: digital health intervention \\ DSM-5: Diagnostic and Statistical Manual of Mental Disorders, Fifth Edition \\ EU: European Union \\ IG: intervention group \\ LZG.NRW: Landeszentrum Gesundheit North Rhine-Westphalia \\ PRISMA: Preferred Reporting Items for Systematic Reviews and Meta-analyses \\ RCT: randomized controlled trial \\ SCID: Structured Clinical Interview for DSM-5 \\ TAU: treatment as usual
}

\author{
Edited by J Torous; submitted 04.12.20; peer-reviewed by S Mathews, J D'Arcey; comments to author 14.12.20; revised version \\ received 15.01.21; accepted 19.02.21; published 16.04.21 \\ Please cite as: \\ Tokgöz P, Hrynyschyn R, Hafner J, Schönfeld S, Dockweiler C \\ Digital Health Interventions in Prevention, Relapse, and Therapy of Mild and Moderate Depression: Scoping Review \\ JMIR Ment Health 2021;8(4):e26268 \\ URL: https://mental.jmir.org/2021/4/e26268 \\ doi: $10.2196 / 26268$ \\ PMID:
}

CPinar Tokgöz, Robert Hrynyschyn, Jessica Hafner, Simone Schönfeld, Christoph Dockweiler. Originally published in JMIR Mental Health (http://mental.jmir.org), 16.04.2021. This is an open-access article distributed under the terms of the Creative Commons Attribution License (https://creativecommons.org/licenses/by/4.0/), which permits unrestricted use, distribution, and reproduction in any medium, provided the original work, first published in JMIR Mental Health, is properly cited. The complete bibliographic information, a link to the original publication on http://mental.jmir.org/, as well as this copyright and license information must be included. 